\title{
Tema:
}

\section{"Prospek Hamba Tuhan Masa Depan: \\ Yang Berhati Hamba, Berjiwa Misioner“}

(Matius 11:28-30)

\section{Oleh: Gunaryo Sudarmanto}

\section{Pendahuluan:}

Tema di atas mengajak berpikir tentang 'personalitas' dan 'tanggung jawab' hamba Tuhan. Personalitas berbicara mengenai 'karakteristik' yang seharusnya ada di dalam diri setiap hamba Tuhan. Sedangkan 'Tanggung jawab' yang dimaksudkan adalah 'misi' sebagai upaya memberitakan kabar baik. Keduanya berhubungan langsung. Karakterisktik hamba yang baik akan berpengaruh secara signifikan terhadap pemberitaan 'kabar baik'. Berturut-turut akan dipaparkan karakteristik seorang yang 'berhati hamba' dan 'berjiwa misioner' yaitu menjadi terang bagi kegelapan dunia melalui 'perbuatan baik'. Kemudian akan dibahas 'perbuatan baik' seperti apakah yang berdaya guna bagi konteks misi masa kini.

\section{A. Kelemahlembutan}

Karakter hamba yang ditekankan dalam Matius 11:28-30 adalah 'kelemahlembutan'. Ketika seseorang mengalami 'kelahiran baru' yaitu menerima Yesus Kristus sebagai Tuhan dan Juruselamat pribadinya, ia juga menerima Roh Kudus dalam dirinya. Kemudian Roh Kudus melengkapinya dengan dua hal penting, yaitu: 'karunia Roh' dan 'buah Roh'. Karunia Roh diberikan sebagai 'alat' untuk melayani dan membangun tubuh Kristus. Buah Roh diberikan untuk menunjukkan karakter Kristen dalam kehidupan orang percaya. Keduanya perlu dikembangkan secara seimbang dalam hidup orang percaya. Buah Roh merupakan sifat-sifat yang baik dan seturut dengan kehendak Allah (Gal. 5:23). Salah satu dari buah Roh adalah 'Kelemahlembutan'.

Kelemahlembutan menjadi salah satu karakter Kristen yang penting. Namun sifat lemah lembut ini sering disalahpahami. Sebagian menganggapnya sebagai sikap yang lemah, 'klemak klemek', malu-malu, takut-takut, dan tidak tegas. Kelemahlembutan justru menunjukkan 
kekuatan/kelebihan, yaitu sikap dapat menguasai diri dan mengontrol kekuatannya dengan benar dan bijaksana serta tidak menyalahgunakannya.

\section{Pengertian:}

1. Bahasa Yunani 'prautes' (self control, chastity; Latin: continentia), rendah hati (Mzm 37:11), tidak sombong. Terletak di antara "marah berlebihan" dan "tidak pernah marah".

2. KJV: gentleness: bhs Inggris sehari-hari: kebaikan (kindness).

3. Ciri-ciri kelemahlembutan:

a. Mutu kehidupan yang bebas dari kesombongan, sikap agresif, dan sikap menang sendiri.

b. Sabar dan lemah lembut terhadap orang lain. Tidak kasar kepada orang lain.

c. Tidak memaksakan kehendak kepada orang lain.

d. Sedia mempertimbangkan dan menghargai pendapat orang lain (Amsal 15:4a). Toleran dan tidak suka menimbulkan permusuhan dan kepahitan dalam dirinya (Tit 3:2-3).

e. Suatu penolakan untuk menggunakan kuasa yang dimiliki untuk menyakiti orang lain. Ketidaksediaan untuk menyerang orang lain dan melukai mereka karena alasan dendam dan dengki.

f. Berhenti memperjuangkan rencana kita dan meyakini bahwa Allah akan berjuang atas nama kita demi terlaksananya rencana-Nya.

\section{Siapa yang memiliki 'kelemahlembutan'?}

1. Kelemahlembutan adalah karakter Allah sendiri yang nampak dalam kehidupan Tuhan Yesus (Mat 11:28-30). Setiap orang percaya harus belajar dari pada-Nya. Dia berkata,"Aku ini lemah lembut" ('gentle' = meek).

2. Musa juga seorang yang lemah lembut lebih dari setiap manusia yang di atas muka bumi (Bil 12:3). Meski dia diperlakukan dengan tidak baik oleh saudara-saudaranya sendiri (Harun dan Miryam), namun ia mampu menahan diri dan tidak menjadi marah kepada mereka. Justru Tuhan yang membela Musa dan menghukum Harun dan Miryam.

3. Daud juga seorang yang lembut hatinya. Dia terus berusaha hidup berkenan kepada Tuhan dan sedia tunduk kepada otoritas Allah.

4. Rasul Paulus mengidentifikasikan bahwa kelemahlembutan menjadi ciri orang yang telah 'dipanggil-Nya' (Ef. 4:1-2)

\section{Manfaat kelemahlembutan:}

1. Dalam ucapan bahagia, Tuhan Yesus menyebut orang yang lemah lembut sebagai orang yang 'berbahagia' atau 'diberkati' dan 'memiliki negeri' (Mat 5:5).

2. Raja Salomo menyebut orang yang lemah lembut seperti 'pohon kehidupan'.

3. Rasul Yakobus menandai bahwa orang yang lemah lembut adalah orang yang mudah dibentuk dan diajar. Ia tidak mudah tersinggung. Sebaliknya, dengan senang hati ia sedia menerima teguran atau kritik (Yak 1:21).

4. Rasul Petrus menyebut orang yang lemah lembut sebagai orang yang 'berharga di mata Allah' (1 Pet 3:4) dan sanggup mempertanggungjawabkan imanya (1 Pet 1416). 
Dari semua uraian tersebut di atas, dapatlah dikatakan:

1. Kelemahlembutan adalah karakter Allah yang ditunjukkan-Nya untuk menyelamatkan manusia berdosa.

2. Setiap orang yang percaya kepada-Nya, menerima Roh Kudus dalam dirinya, yang memberinya 'buah Roh' yang membentuk karakteristik kristianinya.

3. Orang Kristen berkewajiban menunjukkan kelemahlembutannya kepada orang lain agar menjadi kesaksian yang hidup dan berdaya ubah.

4. Kelemahlembutan dinampakan dengan cara:

a. Mengakui segala kemuliaan adalah milik Tuhan (Rm 11:36; Flp 2:7-8)

b. Mengetahui siapa kita dalam Tuhan ( $\mathrm{Rm} 8: 16)$

c. Membuang egoisme dan kerendahan hati yang pura-pura

\section{B. Karakter Hamba Yang Misioner}

Karakteristik hamba memancarkan karakter Kristus. Sebagaimana Yesus adalah 'Terang Dunia' demikianlah para pengikut-Nya juga disebut sebagai 'terang dunia'. Terang adalah Kehidupan. Ia memberi energi kehidupan. Tanpa Terang tidak ada kehidupan, dunia pun gelap dan mati. Terang adalah keindahan, karena terang adalah pancaran sinar aneka warna. Dengan terang dunia menjadi penuh warna dan pesona. Yesuslah 'Terang Dunia'. Barangsiapa yang mengikut-Nya tidak berjalan dalam kegelapan, melainkan ia mempunyai 'terang hidup' (Yoh 8:12). Yesus sedang berbicara tentang misi penyelamatan-Nya atas dunia yang gelap akibat dosa. Kepada para murid-Nya, Ia bersabda,"Kamu adalah terang dunia" (Mat 5:14). Dalam teks Matius 5:14-16 ini menegaskan tentang status, tanggung jawab dan tujuan kehidupan orang percaya berada di dalam dunia ini dan cara menjadi terang.

\section{Status:}

- Yesus berkata, "Kamu adalah TERANG dunia". Yesus sedang berbicara kepada para murid-Nya. Merekalah yang Ia sebut sebagai 'terang dunia'. Mereka adalah orang-orang yang telah dipilih dan dipanggil-Nya menjadi pengikut-Nya. Mereka adalah orang yang telah diselamatkan oleh kasih Kristus. Mereka dahulu hidup dalam kegelapan (dosa) yang harusnya binasa, tetapi oleh anugerah Allah dalam Kristus telah dilepaskan dari kuasa kegelapan dan dipindahkan ke dalam Kerajaan Terang (Kol 1:13). Pada masa kini orang yang percaya kepada Yesus adalah orang yang berhak menjadi 'terang bagi dunia'.

- Kata 'adalah' ditulis dalam bentuk 'present, aktif', yang berarti bahwa status orang percaya sebagai 'terang dunia' berlaku hingga saat ini dan terus berlangsung secara aktif.

- Kata 'dunia' (kosmos) menunjuk kepada 'sistem yang licik' dan gelap serta sedang menuju kepada kebinasaan. Utamanya menunjuk kepada manusia yang sedang dikuasai kegelapan dosa. Olehnya mereka membutuhkan terang kehidupan.

\section{Tanggung jawab:}

- Tanggung jawab orang percaya adalah 'bercahaya' yaitu memancarkan terang Kristus kepada dunia di sekelilingnya. Kata 'bercahaya' itu ditulis dalam bentuk 'aorist, aktif, imperatif' yang berarti bahwa 'bercahaya' itu suatu tanggung jawab yang sudah diterima dan sedang dilaksanakan hingga sekarang, serta harus terus dilaksanakan. 
- Setiap orang percaya memiliki tanggung jawab untuk memiliki pengaruh Kristus bagi orang-orang di sekitarnya.

\section{Tujuan:}

- Terang dunia itu bercahaya dengan tujuan supaya 'dilihat orang' dan 'memuliakan Bapa'. Terang itu dengan sengaja (sadar) dipancarkan dan ditempatkan di tempat yang strategis untuk 'dilihat' orang (bukan pamer atau 'show of power'), melainkan untuk memberi daya pengaruh positif, agar banyak orang mengenal kasih Kristus.

- Tujuan tertinggi adalah 'memuliakan Bapa'. Hal ini penting untuk menguji motivasi tindakan orang percaya. Apakah perbuatan itu memuliakan diri sendiri (egosentris) atau memuliakan Tuhan (theosentris).

\section{Cara Menjadi Terang:}

- Cara menjadi terang nampak dalam 'perbuatan baik'. Perbuatan diekspresikan dalam perkataan dan tindakan nyata.

- Dengan Perkataan: Mazmur 37:30 berkata, "Mulut orang benar mengucapkan hikmat, dan lidahnya mengatakan hukum"

- Dengan tindakan/Perbuatan:

- Kata Tuhan Yesus, "Demikianlah hendaknya terangmu bercahaya di depan orang, supaya mereka melihat perbuatanmu yang baik dan memuliakan Bapamu di sorga" (Mat 5:16).

- Kita menabur dengan "perkataan dan perbuatan" yang baik. Karena itu “Janganlah kita jemu-jemu berbuat baik" (Gal 6:9)

- Iman tanpa perbuatan adalah mati (2:14-26)

- "Dengan demikian tiap-tiap manusia kepunyaan Allah diperlengkapi untuk setiap perbuatan baik" (2 Tim 3:17).

- "Yang tahu berbuat baik, tetapi tidak melakukannya, ia berdosa" (4:17).

- "Kasihilah musuhmu... apabila kamu mengasihi orang yang mengasihi kamu, apakah upahmu ?...bukankah orang yang tidak mengenal Allahpun berbuat demikian ?" (Mat $5: 44-45)$

- "Milikilah cara hidup yang baik di tengah-tengah bangsa-bangsa bukan Yahudi, supaya apabila mereka memfitnah kamu sebagai orang durjana, mereka dapat melihatnya dari perbuatan-perbuatanmu yang baik dan memuliakan Allah pada hari Ia melawat mereka" (1 Pet 2:12).

Dengan demikian, seorang pengikut Kristus sejati tentulah berhati hamba, dan seorang yang berhati hamba tentulah juga seorang yang berjiwa misioner. Statusnya di dalam Kristus menjadikannya sebagai terang bagi kegelapan dunia. Selanjutnya, karakteristik hamba seperti apakah yang relevan bagi konteks misi masa kini?

\section{Konteks Misi Masa Kini}

Kata kunci komunitas manusia di zaman ini adalah 'global' dan 'plural'. Globalisasi telah merasuki setiap dimensi kehidupan. Pluralitas etnik, budaya dan agama, semakin mengglobal. 
Pluralitas global menjadi paradoksal. Ia merupakan kekayaan sekaligus potensi konflik. Fakta di sepanjang sejarah manusia menunjukkan bahwa perbedaan etnik dan religi telah menjadikan manusia bagai 'serigala bagi sesamanya' (homo homini lupus). Konflik horisontal yang terus terjadi, lebih disebabkan oleh sempitnya pemahaman tentang hakikat nilai sesama sebagai akibat dari justifikasi dogmatis yang tidak seimbang. Padahal di setiap komunitas religi dan etnik senantiasa memuat urgensi menghargai kehidupan sesama manusia. Pendekatan teologis telah dilakukan para ahli teologi Kristen, namun sayangnya justru menimbulkan sektarianisme di kalangan Kristen yang terpilah secara eksklusif, inklusif, dan pluralis. Ketiga posisi teologis tersebut berpotensi menimbulkan radikalisme, kompromisme dan sinkretisme. Olehnya perlu pendekatan etis yang berbasis pada teologi multikultural, yaitu suatu teologi yang mendasarkan prinsip-prinsipnya pada cara pandang Allah (Teosentris dan Kristosentris) terhadap hakikat relasi antar sesama manusia.

Teologi Kristen tidak meniadakan kebenaran bahwa "TUHAN baik kepada 'semua' orang (Mzm 145:8). Untuk itu pula Rasul Paulus menyerukan,"...marilah kita berbuat baik kepada semua orang, tetapi terutama kepada kawan-kawan kita seiman" (Gal 6:10). Kata 'terutama' tidak berarti meniadakan aspek universalitasnya, melainkan pada prioritas sesuai tuntutan konteks zamannya. Dalam konteks pluralitas inilah misi Kristen mesti mencirikan karakter Kristus. Secara Kristosentris dapat ditemukan karakteristik perso dan karya Kristus yang menjadi dasar bagi misi Kristen di tengah pluralitas agama. Karakteristik tersebut ditemukan dalam prinsip-prinsip sebagai berikut: 1) Inkarnasi; 2) Universalitas soteriologi; 3) Teokrasi-presentis; 4) Universalitas Karya Roh Kudus; 5) Naturalitas Gereja sebagai tubuh Kristus; 6) Multikulturalitas kekekalan.

\section{Inkarnasi (aspek Kristologis)}

Istilah inkarnasi merupakan bentukan kata Latin: 'in' (masuk) dan 'carne' (daging) yang berarti "masuk ke dalam daging". Istilah ini digunakan secara teologis untuk menunjuk pada fakta "Allah menjadi manusia (daging) di dalam dan melalui Yesus Kristus". Kebenaran ini bersumber dari Yohanes 1:14 khususnya pada frasa, "Firman itu telah menjadi manusia"

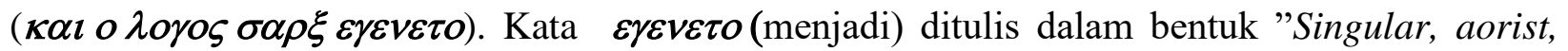
middle, indicative" menunjuk kepada sesuatu yang sudah pernah 'sungguh-sungguh terjadi' secara faktual. Dengan kata lain bahwa peristiwa itu bukan sebuah metafor atau simbolis, dan hasilnya masih dapat dirasakan sampai masa sesudahnya. Hal serupa pernah terjadi pada isteri Lot 'menjadi' tiang garam (Kej.19:26). Artinya secara faktual ia 'sungguh-sungguh menjadi' tiang garam. ${ }^{2}$ Sedangkan kata $\sigma \alpha \rho \xi$ (sark) yang secara harafiah berarti 'daging' digunakan untuk menunjukkan kesungguhan kemanusiaan Yesus. Sebaliknya, kata $\lambda o \gamma o \varsigma$ (logos) diartikan 'Firman' menunjuk pada 'kesungguhan keilahian' Yesus. ${ }^{3}$ Jadi dengan frasa "dan Firman itu telah menjadi manusia" Yohanes menegaskan bahwa yang 'sungguh-sungguh Allah' telah

\footnotetext{
${ }^{1}$ Hasan Susanto (Penyusun), Perjanjian Baru Interlinear Yunani-Indonesia (Jakarta: LAI, 2003), 476.

${ }^{2}$ Donald Guthrie, Teologi Perjanjian Baru, Jilid I (Jakarta: BPK Gunung Mulia, 1995$), 19$.

${ }^{3}$ Leon Morris, The New International Commentary on The New Testament : The Gospel According to John ( Granda Rapdis, Michigan: Wm.B Eerdmans Publishing Company, 1977), 102.
} 
menjadi 'sungguh-sungguh manusia'. Terutama dengan menggunakan kata $\sigma \alpha \rho \xi$, Yohanes melegitimasi kesungguhan realitas kemanusiaan Yesus. Paulus juga menggunakan kata 'sark' untuk menunjukkan hakikat manusia dengan segala kelemahannya (Rm.8:3; Flp.2:7). ${ }^{4}$

Selain secara literal, kemanusiaan Yesus juga dapat dibuktikan dari aspek-aspek fisik, intelektual, emosi, kehendak dan spiritual sebagaimana ciri-ciri manusia pada umumnya. Secara fisik Yesus dilahirkan secara alamiah (Mat.1:25; Luk.2:7). Dia bertumbuh secara normal dari kanak-kanak hingga menjadi dewasa (Luk.2:40). Dia merasa lapar (Mat.21:18) dan haus (Yoh.19:28). Dia mengalami penderitaan dan kematian (Yoh.19:33). Secara mental Dia membutuhkan informasi sehingga perlu bertanya (Mrk.9:21; Luk. 2:46-47). Secara intelektual, Dia belajar Kitab Suci dengan nalar anak Yahudi. Secara emosi, Dia mengasihi keluarga-Nya (Yoh.19:26) dan sahabat-Nya (Mat.23:37). Dia bisa marah (Mrk.19:26), sedih (Mat.9:36). Dia juga memiliki kehendak yang 'berbeda' dengan Bapa-Nya (Mat.26:39). Secara spiritual, Dia berdoa (Mrk.1:35), beriman dan taat kepada Bapa (Flp. 2:8). Jadi dari seluruh aspek tersebut jelas menunjukkan bahwa Yesus 'benar-benar manusia' secara utuh. Dengan menjadi manusia Dia turut merasakan berbagai pencobaan dan penderitaan manusia supaya Dia bisa menolong manusia berdosa (Ibr.2:18; 4:16). Meski dalam segala hal Diasama dengan manusia, namun Dia tidak pernah berbuat dosa (Ibr. 4:15) dan tidak pernah gagal. Yesus adalah Manusia Sejati sebagaimana keadaan manusia ketika ia diciptakan pada mulanya, sebelum jatuh ke dalam dosa. ${ }^{5}$ Karya Kristus ini menunjukkan dua kebenaran penting. Pertama, Solidaritas. Dia yang mulia sedia merendahkan diri, menjadi kecil dan lemah. Dia sedia masuk ke dalam kesakitan dan penderitaan manusia (Fpl.2:6-8). Dia melakukan segalanya demi manusia. Dia memberi makan yang lapar, menyembuhkan yang sakit, mengampuni yang berdosa, menjadi kawan bagi yang tersisih, membangkitkan yang mati. Bahkan Dia juga menjadi korban ketidakadilan. Dia mati menanggung dosa manusia. ${ }^{6}$ Kedua, Identifikasi diri. Kesediaan-Nya menjadi manusia dan sedia memasuki dunia manusia merupakan bentuk 'identifikasi diri' dengan manusia yang dilayani-Nya. Ini merupakan model yang harus ditiru misi kristiani masa kini. Mengenai hal ini, John Stott menyatakan bahwa,

Sebab jika misi kristiani harus mengikuti model misi Kristus, maka tak dapat tidak dalamnya harus tercakup tuntutan yang sama seperti yang telah dipenuhi-Nya, yaitu bahwa kita harus memasuki dunia-dunia orang lain... itu berarti kerelaan meninggalkan kemudahan dan kerterjaminan latarbelakang kebudayaan sendiri, agar dapat mengabdikan diri kepada kepentingan orang-orang dari latar belakang kebudayaan yang lain, yang kebutuhan-kebutuhannya mustahil dapat kita ketahui atau simak sebelumnya. Misi nyata, entah itu pekabaran Injil atau pelayanan sosial atau dua-duanya, menuntut pengidentifikasian diri dengan orang-orang dalam situasi aktual mereka. ${ }^{7}$

\footnotetext{
${ }^{4}$ William Hendriksen, New Testament Commentary: The Gospel of John (Edinburg: The Banner Truth Trust, 1959), 109.

${ }^{5}$ Peter Wongso, Kristologi (Malang: SAAT, 1988), 61-62.

6 John Stott, Isu-isu Global Menantang Kepemimpinan Kristiani (Jakarta : Yayasan Komunikasi Bina Kasih, 1984), 15.

${ }^{7}$ Ibid., 15-16.
} 
Jadi, prinsip solidaritas dan identifikasi diri yang dilakukan Yesus dalam masa inkanasiNya ini merupakan karakteristik yang patut dimiliki oleh setiap 'manusia Tuhan' dalam melaksanakan misinya di tengah pluralitas agama masa kini.

\section{Universalitas Soteriologi (Aspek Soteriologis)}

Pusat karya keselamatan Kristen adalah Kristus. Tujuan utama kedatangan Yesus ke dunia adalah menyelamatkan manusia berdosa. Yang dimaksudkan dengan 'manusia berdosa' ini tentunya bukanlah bangsa Israel saja, melainkan semua bangsa, karena semua orang telah berdosa dan kehilangan kemuliaan Allah (Rm.3:23). Sejak jatuh ke dalam dosa, manusia telah

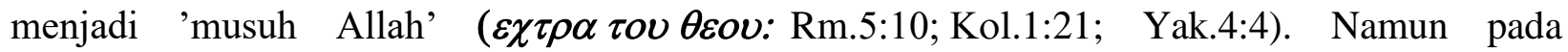
prinsipnya, Allah tidak menghendaki seorangpun binasa, maka setiap orang memiliki kesempatan untuk bertobat, yaitu mengalami pemulihan hubungan (rekonsiliasi) dengan Allah dan sesamanya. Karya keselamatan Allah di dalam dan melalui Kristus disebut juga sebagai 'atonement'. Untuk memahami konsep mengenai karya keselamatan ini, PL menggunakan kata Ibrani (khapar) yang artinya:"to cover by making expiation". Sedangkan PB menggunakan kata Yunani $\kappa \alpha \tau \alpha \lambda \lambda \alpha \gamma \eta$ (katallage) yang berarti:"reconciliation". 8 Rekonsiliasi merupakan bagian sentral dari karya keselamatan Kristus yang sudah dimulai pada masa PL. Dalam PB, rasul Paulus paling banyak menguraikan pokok ini, antara lain dalam Roma 5:10-11 dan II Korintus 5:18-20. Dalam kedua teks tersebut, Paulus memakai istilah $\kappa \alpha \tau \alpha \lambda \lambda \alpha \gamma \eta$ yang diartikan dengan 'pendamaian'. Kata itu berasal dari kata kerja $\kappa \alpha \tau \tau \alpha \lambda \alpha \sigma \omega$ (kattalaso), artinya: "mendamaikan". PB menggunakannya dalam dua konteks, yaitu: konteks hubungan suami dan isteri, dan konteks hubungan Allah dan manusia. ${ }^{9} \kappa \alpha \tau \alpha \lambda \lambda \alpha \sigma \omega$ dibentuk dari kata $\alpha \lambda \lambda \alpha \sigma \sigma \omega$ (allaso) yang artinya:"mengubah" (to change). Sedangkan $\alpha \lambda \lambda \alpha \sigma \omega$ sendiri berasal dari kata $\alpha \lambda \lambda \omega \sigma$ (allos) yang berarti:"lain atau yang lain" (other, another). Jadi secara esensial, $\kappa \alpha \tau \alpha \lambda \lambda \alpha \sigma \omega$ memiliki pengertian dasar "mengubah menjadi lain". ${ }^{10}$ Dalam konteks karya keselamatan manusia $\kappa \alpha \tau \alpha \lambda \lambda \alpha \sigma \omega$ dimaksudkan untuk mengubah manusia sebagai 'musuh Allah' menjadi 'kekasih Allah' ( $\alpha \gamma \alpha \pi \eta \tau o \sigma)$. Untuk maksud itu Kristus datang ke dunia yaitu menyelamatkan setiap orang yang percaya kepada-Nya (Yoh.3:16).

Karya keselamatan tersebut terbuka untuk semua orang (universal). Sebab itu, sebelum kenaikan-Nya ke sorga, Yesus memberikan Amanat Agung-Nya kepada murid-Nya untuk menjadi saksi-Nya dari Yerusalem, Yudea, Samaria dan sampai ujung bumi. Amanat ini, "...menegaskan bahwa Injil sebagai satu-satunya kebenaran universal harus disampaikan kepada segenap umat manusia pada segala tempat dan waktu (universal)". ${ }^{11}$ Selain berita Injil tersebut dimaksudkan untuk pemulihan hubungan dengan Allah, namun akibatnya juga akan terjadi pemulihan hubungan antar sesama manusia.

Prinsip universalitas keselamatan ini merupakan dasar bagi hubungan multikultur, karena setiap orang dengan etnis dan religinya memiliki kesempatan untuk percaya kepada Kristus dan

${ }^{8}$ Archibal A. Hodge, The Atonement (London: Evangelical Pree, 1974), 33.

${ }^{9}$ Buchel, $\kappa \alpha \tau \alpha \lambda \lambda \alpha \gamma \eta$ dalam Kittel, 255.

${ }^{10}$ Robert L. Thomas (Ed.), New American Standard Exhaustive Concordance of The Bible (Nashville: Holman Bible Publisher, 1981), 1629, 1630, 1659.

${ }^{11}$ Elisa B. Surbakti, Benarkah Yesus Juruselamat Universal? (Jakarta: BPK Gunung Mulia, 2006), 55. 
menerima keselamatan. Karena itu, hubungan multikultural haruslah dipandang dari dua perspektif sekaligus, yaitu: keharusan untuk hidup dalam damai dengan orang lain, dan memanfaatkan hubungan multikultur sebagai kesempatan untuk memberitakan kabar keselamatan kepada semua orang. Karena itu Injil juga harus diberitakan melalui aspek-aspek budaya orang lain. Keterbukaan dengan semua orang, dari berbagai lapisan, golongan, suku dan bangsa, merupakan karakteristik Kristus yang patut diteladani dalam misi Kristen masa kini.

\section{Teokrasi-presentis (Aspek Teokratis)}

Yang dimaksudkan dengan 'Teokrasi' ialah 'pemerintahan Allah' dimana Allah memerintah sebagai 'Raja' dalam 'Kerajaan-Nya'. Dengan kata lain Teokrasi berbicara

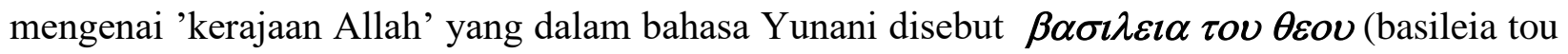
theou). Istilah Yunani $\beta \alpha \sigma \imath \lambda \varepsilon \imath \alpha$ dari kata $\beta \alpha \sigma \imath \lambda \varepsilon \imath v \zeta$ (basileus) yang berarti: 'raja'. ${ }^{12}$ Dalam pemikiran Yunani basileus menunjuk kepada seorang raja yang sah menurut hukum dan biasanya secara turun-temurun menjadi pemimpin religius atas rakyatnya. ${ }^{13}$ Sedangkan istilah $\beta \alpha \sigma \imath \lambda \varepsilon \imath \alpha$ (basileia) yang berarti: pertama, "royal, power, kingship, dominion, rule". Kedua, "a kingdom". Arti yang pertama menunjuk kepada 'kuasa atau wewenang' yang dimiliki oleh seorang raja. Sedangkan yang kedua menunjuk kepada 'wilayah' kekuasaan seorang raja.

Kemudian dalam Alkitab istilah 'kerajaan' digunakan dalam hubungannya dengan Allah,

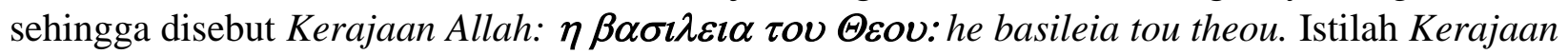
Allah itu sendiri digunakan oleh Yesus dalam pemberitaan-Nya seperti termaktub dalam Injil Sinoptis, yang juga sinonim dengan Kerajaan Sorga (Mat.4:17; 5:3; Mrk. 1:15; Luk.6:20) dan Kerajaan Bapa (Mat.26:29). Istilah Kerajaan Allah dan Kerajaan Sorga secara literal tidak terdapat dalam Perjanjian Lama, sehingga pengertiannya juga belum begitu jelas dalam agama Yahudi. Namun demikian akar dan ide yang terkandung di dalamnya sudah terdapat secara samar dalam Perjanjian Lama dan dalam pengharapan iman umat Israel. Karena itu istilah Kerajaan Sorga tidak ditemukan dalam tulisan-tulisan Yahudi-Yunani, namun sudah terdapat dalam literatur Talmud (malkuth shamayim) sebagai literatur yang lebih tua. Hal itu menunjukkan bahwa pemahaman dasar tentang Kerajaan Sorga telah disimpan lama dalam idiom Yahudi. $^{14}$

Jadi 'kerajaan Allah' dapat berarti: pemerintahan Allah, kekuasaan Allah, dan kedaulatan Allah yang bersifat universal (Bnd Mzm.103:19; 145:11,13; Dan.2:37; Luk.19:1112). Secara terminologis Alkitabiah pengertian 'kerajaan Allah' lebih menunjuk kepada kedudukan-Nya sebagai raja atau pemerintahan-Nya dan kedaulatan-Nya. ${ }^{15}$ Kerajaan Allah ini menunjuk kepada Kristus sebagai Raja yang sudah datang, memulai kerajaan-Nya dan akan datang di masa mendatang (Future). Karena itu 'basileia tou theou' tidak hanya dimengerti sebagai The Kingdom of God (Kerajaan Allah) melainkan God's Kingship (Kepemerintahan

12 B. Klappert, "King, Kingdom" dalam Colin Brown, The New International Dictionary of New Testament Theology, Vol. 2 (Grand Rapids, Michigan: Zondervan Publishing House, 1976), 372.

${ }^{13}$ Kleinknecht, " $\beta \alpha \sigma \imath \lambda \varepsilon \cup \zeta$ in The Greek World" dalam Gerhart Kittel (Ed.), Theological Dictionary of New Testament, Vol. 1 (Grand Rapids, Michigan: Wm.B. Eerdmans Publishing Company, tt), 564.

14 George Eldon Ladd, Crucial Question About The Kingdom of God (Grand Rapids, Michigan: Wm.B. Eerdmans Publishing Company, 1952), 121-122.

${ }^{15}$ George Eldon Ladd, Injil Kerajaan (Malang: Gandum Mas, 1999), 21-23. 
Allah). Kingship of God lebih menunjuk kepada sebuah situasi yang luas yang meliputi seluruh kehidupan yang di dalamnya Allah memerintah sebagai Raja. Dalam pengertian ini Allah menjadi pemilik dari seluruh kehidupan pada masa kini dan masa yang akan datang. ${ }^{16}$ Eka Darmaputera menambahkan bahwa 'Kerajaan Allah' merupakan terminologi dalam teologi Kristen yang menunjuk kepada," suatu keadaan atau kenyataan dimana Allah dengan spenuhnya akan memerintah dan memberlakukan kehendak-Nya, yaitu keadilan, kebenaran, perdamaian dan kesejahteraan yang menyeluruh bagi seluruh umat manusia". ${ }^{17}$ Itu berarti Kerajaan Allah tidak hanya bersifat futuris, melainkan juga memuat dimensi presentis. Hal itu sudah dinyatakan ketika Yohanes Pembaptis berseru, "Bertobatlah, sebab Kerajaan Sorga sudah dekat!” (Mat.3:2). Frasa 'sudah dekat' diterjemahkan dari kata Yunani $\boldsymbol{\eta} \gamma \boldsymbol{\imath} \boldsymbol{\imath} \boldsymbol{\varepsilon} \boldsymbol{v}$ (eggiken) yang merupakan bentuk 'perfek aktif indikatif' dari $\varepsilon \gamma \gamma \mathbf{} \boldsymbol{\zeta} \zeta \omega$ (eggidzo) yang berarti: "to come near, approach, or draw nigh". WE Best menjelaskan pengertian dasar dari ketiga kata Inggris tersebut,

There is much discussion over the following statement in the King James translation of the Bible:"the Kingdom of heaven is at hand" (Matt. 3:2; 4:17; 10:7). The Greek verb in those verses is eggiken, perfect active indicative of eggidzo, which means to come near, approach, or draw nigh. When we observe the basic English meaning of these three verbs, we can better determine the definition of eggidzo. "Come" means to come toward or away from something, to pass from one point to one nearer. "Draw" means to pull, drag, draw, or move toward. "Approach" means to come or go near or nearer in either place or time. The accurance of eggidzo in its perfect active indicative form in each reference where it is used proves that the kingdom has not arrived, but it has approach or come near. $^{18}$

Dengan demikian dapat dikatakan bahwa Kerajaan Allah itu memang 'sudah dekat' atau sama dengan 'belum sampai'. Namun tidak berarti 'masih sangat jauh' sehingga sama sekali tidak dapat dilihat dan dirasakan kehadirannya. Maksud dari kata eggiken adalah bahwa kehadirannya telah begitu dekat dan sangat dapat dirasakan. Bentuk 'perfek' yang digunakan menegaskan bahwa 'kerajaan' yang dimaksudkan dalam nubuatan PL telah benar-benar tergenapi.

Presensi Kerajaan Allah itu semakin jelas ketika Yesus memulai pelayanan-Nya di Galilea dan menyatakan,'Waktunya telah genap, Kerajaan Allah sudah dekat. Bertobatlah dan percayalah kepada Injil!" (Mrk.4:15). Kata Yunani yang diterjemahkan dengan 'waktu' adalah kata $\kappa \alpha \iota \rho o \sigma$ (kairos) yang berarti 'saat' atau 'waktu tertentu', bukan $\kappa \rho o v o \sigma$ (kronos) yaitu waktu yang berlangsung terus menerus. 'Kairos' itulah yang dipakai Yesus untuk menunjukkan penggenapan di dalam Diri-Nya. Herman Ridderbos menjelaskan pengertian 'kairos' sebagai berikut:

\footnotetext{
16 Weinata Sairin, Victor I. Tanya, Eka Darmaputera, "Berbagai Dimensi Kerukunan Hidup Umat Beragama" dalam Weinata Sairin (Peny.), Kerukunan Umat Beragama Pilar Utama Kerukunan Berbangsa (Jakarta: BPK Gunung Mulia, 2006), 18.

17 Eka Darmaputera, "Tugas Panggilan Bersama Agama-agama di Indonesia” dalam. J. Garang (Peny.), Peranan Agama-agama dan Kepercayaan Terhadap Tuhan yang Maha Esa Dalam Negara Pancasila yang Membangun (Jakarta: BPK Gunung Mulia, 1996), 141.

18 W.E. Best, Christ's Kingdom Is Future, Vol. II (Houston, Texas: South Belt Assembly of Christ, tt), 159.
} 
Therefore, kairos means the great moment of commencement of the great future appointed by God in His counsel, and announced by the prophets. By the side of "is at hand" there is already the "is fulfilled". No doubt the two expressions shoult be understood in connection with each other. "At hand" in expression "is at hand" does not mean the same thing as "has come", "is present", as clearly appears from the purpose of John's preaching. The expression "the time is fulfilled" will thus have to be understood as the indication that the threhold of the great future has been reached, that the door has been opened, and that the prerequisites of the realization of the divine work of consummation are present; so that now the concluding divine drama can start. ${ }^{19}$

Jadi, "waktunya telah genap" berarti bahwa melalui kehadiran Yesus 'masa yang akan datang' sedang dimulai. Hal itu lebih ditegaskan oleh Yesus ketika Ia berkhotbah di Nazaret (Luk.4:16-30). Dalam ibadah di Sinagoge itu Ia membaca nubuat dari kitab Yesaya 61:1-2 mengenai "tahun rahmat Tuhan". Pada saat itulah Yesus menegaskan:"Pada hari ini genaplah nas ini..." (ay.21). Dengan penegasan tersebut, Yesus sedang menunjuk Diri-Nya sendiri sebagai penggenapan dari nubuatan Yesaya. Itu berarti bahwa 'Person yang diurapi Tuhan' dan 'yang disertai Roh Tuhan', seperti yang dimaksudkan oleh Yesaya, ialah Yesus sendiri. Dialah yang dimaksudkan yang akan memberitakan kabar baik kepada orang miskin, pembebasan kepada tawanan, mencelikkan yang buta, membebaskan yang tertindas, dan memberitakan tahun rahmat Tuhan.

Hal tersebut ditegaskan kembali oleh Yesus ketika menjawab pertanyaan murid-murid Yohanes Pembaptis tentang jatidiri-Nya sebagai Mesias. Yesus menjawab pertanyaan itu dengan menyebutkan tindakan-tindakan Mesianis-Nya, yaitu:"...orang buta melihat, orang lumpuh berjalan, orang kusta menjadi tahir, orang tuli mendengar, orang mati dibangkitkan dan kepada orang miskin diberitakan kabar baik" (Luk.7:18-22). Meskipun Yesus hanya menyebutkan karya-Nya, namun hal itu sekaligus mengindikasikan jatidiri-Nya sebagai Mesias. Dalam hal ini nyata kesatuan karya dan Person Mesias dalam Diri Yesus.

Selanjutnya, presensi Kerajaan Allah diperjelas oleh tanda-tanda yang dinyatakan Yesus melalui pengajaran dan karya-karya-Nya. Secara umum ada enam tanda yang menunjukkan presensi Kerajaan Allah, yaitu:

Pertama, pemberitaan kabar baik kepada orang miskin. Tanda ini dinyatakan tiga kali oleh Yesus, yaitu: dalam khotbah di Nazaret (Luk.4:18), dalam jawaban-Nya atas keraguan Yohanes Pembaptis di penjara (Mat.11:5; Luk. 7:22), dan dalam ucapan bahagia (Mat.5:3; Luk.6:20). Kata 'miskin' yang dimaksudkan adalah pertama-tama menunjuk kepada 'orang desa' (amhaarezt). Mereka adalah penduduk Israel yang kurang memahami Hukum Taurat, karena tidak mendapatkan pengajaran semestinya dari orang Farisi dan ahli Taurat. Mereka tidak diperhatikan dan dianggap berperilaku tidak senonoh, sehingga dianggap berada di luar keselamatan. Dengan demikian di dalam kemiskinan jasmani itu terkandung juga kesusahan rohani yang terus menantikan datangnya keselamatan atas dirinya. ${ }^{20}$

19 Herman Ridderbos, The Coming of The Kingdom (Philadelphia: Presbyterian and Reform Publishing Company, 1973), 48.

${ }^{20}$ Ulrich Beyer, Garis-garis Besar Eskatologi Dalam Perjanjian Baru (Jakarta: BPK Gunung Mulia, 1982$), 16$. 
Kata 'miskin' juga bisa diartikan sebagai orang yang mengalami kesulitan jasmani, menanggung sengsara, teraniaya dalam masyarakat dan mengeluh di bawah kejahatan sosial orang-orang yang egois. Tetapi mereka juga adalah orang yang rendah hati, lembut hati, senantiasa menantikan keselamatan yang dijanjikan Allah kepada umat-Nya. Kepada merekalah Injil Kerajaan Allah diberitakan sebagai penggenapan janji keselamatan-Nya. ${ }^{21}$ Pengertian tersebut juga berkaitan dengan pernyataan Yesus dalam Matius 5:3,"Berbahagialah orang yang miskin di hadapan Allah, karena merekalah yang empunya Kerajaan Sorga". Dalam ayat itu, kata 'miskin' lebih bersifat rohani daripada jasmani. Frasa "merekalah yang empunya Kerajaan Sorga" berarti Kerajaan Sorga menjadi milik mereka dalam arti rohani. Sebagai contoh, Yesus mengajarkan perumpamaan tentang orang Farisi dan pemungut cukai (Luk.18:9-14). Keduanya bersama-sama berdoa di Bait Allah. Dalam doanya orang, Farisi sangat bangga dengan segala 'kebaikan' rohaninya. Sedangkan pemungut cukai dengan hancur hati menyadari keberdosaannya. Tentang pemungut cukai itu Yesus berkata:"orang ini pulang ke rumahnya sebagai orang yang dibenarkan Allah dan orang lain itu tidak" (ay.4). ${ }^{22}$ Mengomentari ayat tersebut Charles L. Allen menyatakan:"The first key to God's Kingdom is another type of poverty...the poverty which is a key to God's Kingdom is realization that, though we posses all things, without God all our things are nothing." ${ }^{23}$ Itulah aspek utama yang diperhatikan Yesus, sehingga mereka perlu mendengarkan Injil agar mereka mengalami keselamatan dari dosa.

Kedua, kehadiran Kerajaan Allah ditandai dengan Pengampunan dosa. Yesus menegaskan kembali nubuat Yesaya tentang, "Pembebasan bagi tawanan dan orang yang tertindas" (Luk.4:19). Pernyataan itu hanya dapat dimengerti dalam hubungannya dengan pengampunan dosa, karena terkait erat dengan tahun rahmat Tuhan atau tahun Yobel. Di tahun itu, menurut tradisi Israel, seorang yang miskin dan telah menjadi budak harus dibebaskan dari segala hutangnya dan dimerdekakan (Bnd. Im.25:39, dst; Yeh.46:17). Searah dengan nubuatan tersebut, Yesus memberikan pengampunan dosa agar orang yang tertawan dan tertindas oleh dosanya dilepaskan dan diampuni. Matthew Henry dalam komentarnya menyatakan:'The Gospel is a proclamation of liberty, like that to Israel in Egypt and in Babylon. It is a deliverence from the worst of thraldoms, which all those shall have the benefit of that are willing to make Christ their Head". ${ }^{24}$ Pembebasan yang utama ialah pembebasan dari dosa. Karena itu Yesus memberitakan tentang pengampunan dosa dan melakukan pengampunan dosa (Mrk.2:5). Tindakan tersebut merupakan proklamasi ke-Allahan-Nya dimana Ia menunjukkan hak prerogatif Allah untuk mengampuni manusia berdosa. Untuk itu Ia bergaul dengan orang-orang yang dianggap paling berdosa seperti: pemungut cukai dan wanita pezinah, karena mereka juga berhak masuk ke dalam Kerajaan Allah. Kepada para pemimpin agama Yahudi, Yesus menegaskan,"pemungutpemungut cukai dan perempuan-perempuan sundal akan mendahului kamu masuk ke dalam Kerajaan Allah (Mat.21:31). Ayat itu menunjukkan sifat kekinian dari Kerajaan Allah, karena orang-orang berdosa itu sedang menjadi warga Kerajaan Allah. Itu berarti Yesus menyatakan bahwa Kerajaan Allah sudah hadir dan dimulai di bumi. ${ }^{25}$

${ }^{21}$ Herman Ridderbos dan Baarlink, Pemberitaan Yesus Menurut Injil Sinoptis (Jakarta: BPK Gunung Mulia, 1975), 72-75.

22 Peter Wongso, Hermeneutika Eskatologi (Malang: SAAT, 1989), 91.

${ }^{23}$ Charles L. Allen, God's Psichiatry (New Jersey: Fleming H. Revell Company, 1970), 130-131.

${ }^{24}$ Matthew Henry, Matthew's Henry Commentary (Grand Rapids, Michigan: Zondervan Publishing Company, 1979), 1425.

${ }^{25}$ Donald Guthrie, Teologi Perjanjian Baru (Jakarta: BPK Gunung Mulia, 1993), 26. 
Ketiga, Yesus melakukan Mujizat. Matius 8:17; 11:5; Luk 7:16 mendaftarkan tindakan kemesiasan Yesus sebagaimana dinubuatkan Yesaya 35:5b; 29:18-19 dimana "orang uta melihat,orang lumpuh berjalan, orang kusta menjadi tahir, orang tuli mendengar dan orang mati dibangkitkan". Esensi dari mujizat tersebut ialah penyataan Kerajaan Allah sebagai tindakan penyelamatan oleh Mesias. Jadi dengan melakukan mujizat, sebenarnya Yesus sedang menunjukkan kehadiran-Nya sebagai Raja yang berkuasa. ${ }^{26}$

Keempat, Pengusiran setan. Secara eksplisit Yesus sendiri telah menyatakan hubungan langsung antara pengusiran setan dengan kehadiran Kerajaan Allah. Ia berkata,'Jika Aku mengusir setan dengan kuasa Roh Allah, sesungguhnya Kerajaan Allah sudah datang kepadamu" (Mat.12:28; Luk. 11:20). George Eldon Ladd menyatakan,'Tindakan pengusiran roh-roh jahat membuktikan bahwa Kerajaan Allah sudah datang dan sedang bekerja di antara umat manusia. Pengusiran roh jahat itu sendiri merupakan pekerjaan Kerajaan Allah". ${ }^{27}$ Jelaslah bahwa pengusiran setan oleh Yesus membuktikan kekalahan kuasa setan atas kuasa Allah yang telah hadir di dalam dan melalui Yesus. Dengan kata lain, terusirnya setan menyatakan kehadiran Kerajaan Allah.

Kelima, Perumpamaan. Untuk mengajarkan tentang kerajaan Allah, Yesus kerapkali menjelaskannya melalui sebuah perumpamaan, yaitu cerita yang diambil dari kehidupan manusia sehari-hari dan dirancang untuk menggambarkan kebenaran utama dari apa yang akan diberitakan. Perumpamaan begitu penting, sehingga menguasai hampir sepertiga dari pengajaran Yesus. ${ }^{28}$ Dalam Markus 4 dan Matius 13 terdapat kumpulan perumpamaan tentang 'rahasia Kerajaan Allah'. Melalui perumpamaan-perumpamaan tersebut, Yesus menyatakan kehadiran Kerajaan Allah sebagai revolusi Allah dalam sejarah. David Wenham dalam bukunya The Parables of Jesus: Pictures of Revolution menjelaskan,

...in proclaiming the kingdom of God, Jesus was announcing the coming of God's revolution and God's new world, as promised in the Old Testament. God was at last intervening, Jesus declared, to establish his reign over everything, to bring salvation to his people and renewal and reconciliation to the world. But fortunetely Jesus did not announce his message in such general theological terms, he announced it primarily through vivid, concrete parables. ${ }^{29}$

Jadi, melalui perumpamaan yang disampaikan, Yesus menegaskan bahwa Kerajaan Allah telah dinyatakan dan hadir dalam sejarah manusia masa kini. Keenam, Peristiwa di sekitar Yesus melebihi kehebatan peristiwa dalam PL. Yesus menyatakan hal itu ketika berkata,"sesungguhnya yang ada di sini lebih besar daripada Yunus" dan "lebih daripada Salomo" (Mat.12:41-42). Peristiwa Yunus dan pertobatan orang Niniwe merupakan peristiwa yang menakjubkan. Tetapi Yunus hanya memberitakan tentang kebenaran Allah, sedangkan Yesus adalah kebenaran itu sendiri. Demikian juga dengan hikmat Salomo yang begitu tinggi, sehingga mempesona setiap orang yang mendengarnya. Namun, Salomo tidak dapat memberikan hikmatnya kepada siapapun, sedangkan Yesus adalah Hikmat itu sendiri dan memberikan kepada siapa saja yang

\footnotetext{
${ }^{26}$ Ridderbos dan Baarlink, 36-38.

${ }^{27}$ George E. Ladd, A Theology of The New Testament (Grand Rapids, Michigan: Wm. B. Eerdmans Publishing Company, 1987), 56.

28 A.M. Hunter, Menafsirkan Perumpamaan-perumpamaan Yesus (Jakarta: BPK Gunung Mulia, 2000), 1, 11.

${ }^{29}$ David Wenham, The Parables of Jesus: Pictures of Revolution (London: Hodder \& Stoughton, 1989), 25.
} 
datang kepada-Nya serta menyelamatkannya. Karena itu Ia menegaskan,"Sesungguhnya banyak nabi dan orang benar ingin melihat apa yang kamu lihat, tetapi tidak melihatnya dan ingin mendengar apa yang kamu dengar, tetapi tidak mendengarnya" (Mat.13:17). ${ }^{30}$ Artinya, di dalam dan melalui Yesus terjadi peristiwa-peristiwa yang melebihi peristiwa sebelumnya. Itu disebabkan Yesus sendiri ialah Mesias yang oleh-Nya Allah melawat umat-Nya dengan kasihNya sebagaimana telah dijanjikan sebelumnya (Luk.7:16; Mat.11:2-6).Dengan kedatangan Yesus berarti masa eskatologis sudah mulai diwujudkan pada masa kini.

Selain bukti-bukti kehadiran Kerajaan Allah pada masa kini tersebut di atas, 'Kerajaan Kristus' juga dapat dipahami dalam dua aspek pengertian, yaitu: regnum potentiae dan regnum gratiae. Yang dimaksud dengan regnum gratiae adalah jabatan Kristus sebagai Raja Rohani atas umat-Nya atau Gereja-Nya. Kerajaan ini bersifat rohani yang didasarkan pada karya penebusan Kristus. Kerajaan rohani ini sudah ada pada masa sekarang mapun masa yang akan datang. ${ }^{31}$ Sedangkan yang dimaksud dengan regnum potentiae adalah kekuasaan Kristus atas alam semesta yaitu pemerintahan-Nya secara providensial dan yuridis atas segala sesuatu dalam hubunganya dengan Gereja. Lebih lanjut Berkhof menjelaskan bahwa, sebagai Raja alam semesta, Sang Pengantara memimpin dan menentukan setiap pribadi individual, dari kelompok sosial, dan bangsa-bangsa, untuk menentukan pertumbuhan, penyucian sedikit demi sedikit, dan kesempurnaan akhir dari umat-Nya yang telah Ia tebus dengan darah-Nya...Kristus sekarang mengatur jalan hidup setiap individu dan bangsa yang termasuk dalam gereja yang telah disatukan oleh darah-Nya... ${ }^{32}$

Jadi dari aspek regnum potentiae, pemerintahan Kristus atas alam semesta berkuasa mengatur segala bangsa untuk melindungi umat-Nya. Dalam hal ini nampak hubungan tak terpisahkan antara umat-Nya dengan bangsa-bangsa. Sebab itu gereja tidaklah seharusnya berusaha memisahkan diri dari bangsa-bangsa (multikultur), namun sebaliknya harus mengintensifkan hubungan dengan bangsa-bangsa. Dalam hal ini gereja menyatakan keharmonisan sosial sebagai bagian dari rencana perwujudan Kerajaan Allah dalam aspek kekinian. Gereja memiliki tanggung jawab sosial yang menyatukannya dengan masyarakat. Gereja dan masyarakat tidak dapat dipisahkan melainkan saling melengkapi. ${ }^{33} \mathrm{H}$. Henry Meeter menegaskan bahwa sorga dibawa ke dalam material (dunia nyata). Dimensi rohani menerangi dunia materi (sosial) supaya terjadi pemulihan. Tuhan mendelegasikan orang percaya untuk membangun dan memelihara tatanan sosial. ${ }^{34}$ Teokrasi presentis dalam aspek inilah yang menjadi dasar bagi orang percaya untuk berelasi dengan sebaik-baiknya secara multietnis dan multireligi.

\section{Universalitas karya Roh Kudus (Aspek Pneumatologis)}

Pemberitaan karya Allah diteruskan oleh Roh Kudus ke seluruh dunia di segala abad. Roh Kudus adalah utusan Kristus untuk mengaplikasikan karya Kristus kepada semua manusia.

\footnotetext{
${ }^{30}$ Beyer, 22.

${ }^{31}$ Louis Berkhof, Teologi Sistematika 3: Doktrin Kristus (Jakarta: LRII, 1998), 234-242.

${ }^{32}$ Ibid., 242-243.

${ }^{33}$ Ernst Troeltsch, Protestanism and Progres, A History of the Relation of Protestanism to the Modern World (Beacon: Beacon, 1958), 57.

${ }^{34}$ H. Henry Meeter, The Sovereignty of The Social Sphere (Michigan: Baker, 1975), 125.
} 
Roh Kudus inilah yang dijanjikan Kristus sebagai yang akan memberi kuasa untuk menjadi saksi Kristus (Kis.1:8). Dinamika Roh Kudus yang memampukan para murid Kristus untuk menjadi saksi-saksi Kristus sampai ke ujung bumi. Dalam hal ini Roh Kudus menindak lanjuti penugasan Kristus untuk menjadikan sekalian bangsa murid-Nya (Mat.28:19-20). Dengan tugas ini menunjukkan adanya aspek universalitas karya Roh Kudus itu. Pada peristiwa Pentakosta, universalitas tersebut mulai memanifestasi dalam bentuk 'bahasa-bahasa' dari berbagai etnis (Partia, Media, Elam, Mesopotamia, Yudea, Kapadokia, Pontus, Asia, Frigia, Pamfilia, Mesir, Libia, Roma, Yahudi, Kreta, dan Arab = Kis.2:8-11). Jadi Roh Kudus yang mendinamisasi orang percaya untuk memberitakan Injil kepada segala bangsa (panta ta ethne). H.Berkhof sebagaimana dikutip oleh Abineno menyatakan,"Roh Yesus Kristus - yaitu Roh yang mengandung kuasa yang membebaskan dan yang membaharui - sedang bekerja di segala tempat,di mana manusia dilepaskan dari keganasan alam, negara, warna kulit, kasta, kelas, kelamin, kemiskinan, penyakit, kebodohan dan lain-lain..." ${ }^{35}$ Lebih lanjut Abineno sendiri menegaskan bahwa karya Roh Kudus tidak hanya terbatas pada Gereja saja, melainkan mencakup seluruh dunia. ${ }^{36}$ Atas dasar itu, maka orang yang telah ditebus oleh karya Kristus dan menerima Roh Kudus dalam dirinya pastilah didorong untuk terus berkomunikasi dengan orang lain yang beda etis dan agama untuk menjadi saksi Kristus kepada mereka.

Selain itu, Roh Kudus juga memberi buah dalam hidup orang percaya berupa: kasih, sukacita, damai sejahtera, kesabaran, kemurahan, kebaikan, kesetiaan, kelemahlembutan dan penguasaan diri (Gal.5:23). Buah Roh ini merupakan potensi pada diri orang percaya untuk diaktualisasikan dalam hubungannya dengan orang lain, baik teman seiman maupun beda iman. Misalnya, istilah 'kasih' yang diterjemahkan dari 'agape' berarti: "love, concern, interest, sacred meal shared by the early church" (kasih, kepedulian, minat, makanan kudus yang dibagikan oleh gereja mula-mula). ${ }^{37}$ Makna yang jelas dari 'agape' adalah kasih dan kepedulian yang mencakup kasih kepada semua orang. Josias Lengkong menyimpulkan,"...kasih sebagai buah Roh tidak bersikap diskriminatif dan memperlakukan orang-orang lain dengan keprihatinan yang mendalam...Rasa cemburu yang banyak merusak hubungan antar pribadi, antar golongan dan antar umat beragama, akan dengan sendirinya ditinggalkan". ${ }^{38}$ Hal ini juga menjadi dasar untuk melakukan 'kebaikan' kepada yang beda etnis dan religinya.

\section{Naturalitas Gereja (Aspek Eklesiologis)}

Gereja adalah tubuh Kristus, dan Kristus adalah kepala gereja. Septuaginta menggunakan istilah Yunani $\varepsilon \kappa \kappa \alpha \lambda \varepsilon \omega$ (ekkaleo) yang artinya: 'memanggil keluar'. Dari kata Yunani ini, Perjanjian Baru menggunakan kata $\varepsilon \kappa \kappa \lambda \varepsilon \sigma \iota \boldsymbol{\alpha}$ (ekklesia) sebagai bentukan dari kata $\boldsymbol{\varepsilon} \kappa(e k)$ dan $\kappa \alpha \lambda \varepsilon \omega$ (kaleo) yang berarti:'dipanggil keluar'. Kata ini dimengerti dalam hubungannya dengan karya Kristus yang telah menjadi juruselamat manusia berdosa. Sehingga secara esensial kata $\boldsymbol{\varepsilon} \kappa \boldsymbol{\kappa} \lambda \boldsymbol{\varepsilon} \sigma \boldsymbol{l} \alpha$ dimengerti sebagai 'persekutuan orang yang telah dipanggil keluar dari dunia ini

\footnotetext{
${ }^{35}$ J.L.Ch. Abineno, Roh Kudus dan Pekerjaan-Nya (Jakarta: BPK Gunung Mulia, 1982), 144.

${ }^{36}$ Ibid., 145

${ }^{37}$ Barclay M. Newman, A Concise Greek-English Dictionary Of The New Testament (London: United Bible Societies, 1971), 2.

38 Josias L. Lengkong, Jihad Kristen: Adakah kesamaan Jihad Islam dan Jihad Kristen? (Jakarta: Yayasan Misi Global Kalimatullah, 2003), 306-307.
} 
untuk menjadi milik Allah'. ${ }^{39}$ Dengan demikian pengertian $\boldsymbol{\varepsilon} \kappa \boldsymbol{\kappa} \boldsymbol{\lambda} \boldsymbol{\varepsilon} \sigma \boldsymbol{\iota} \boldsymbol{\alpha}$ juga menunjukkan

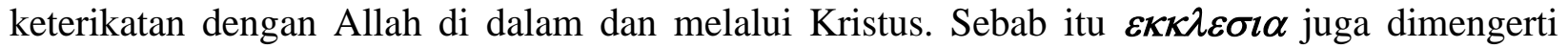
sebagai 'jemaat Allah' dengan maksud yang sama seperti qahal yahwe dalam Perjanjian Lama.

Pemahaman Yesus tentang 'jemaat Allah' nampak dalam misi pelayanan dan pengajaranNya yang berkesinambungan dengan pemahaman Perjanjian Lama. Yesus memfokuskan pelayanan-Nya kepada orang Yahudi yang disebut-Nya sebagai "domba-domba yang hilang dari umat Israel" (Mat.15:24) yang secara esensial sama dengan 'umat Allah'. Namun kemudian Yesus memperluas pengertian 'domba yang hilang' juga dikenakan kepada murid-Nya yang 'tercerai-berai' (Luk.12:32; Mrk.14:27; bnd. Zak.13:7). Meskipun Yesus menujukan misi keselamatan-Nya kepada orang Yahudi, namun Ia juga menyadari bahwa mereka akhirnya akan menolak-Nya. Sebab itu terjadi transformasi pengertian 'umat Allah' yang tidak saja ditujukan kepada 'umat Israel' melainkan juga kepada para murid-Nya dan semua orang yang percaya kepada-Nya (bnd. Mat.3:9; Luk.3:8). Yesus menggunakan istilah $\boldsymbol{\varepsilon} \kappa \kappa \lambda \varepsilon \sigma \iota \boldsymbol{\alpha}$ tidak dimaksudkan menunjuk kepada suatu organisasi, tetapi sekelompok orang yang dianggap-Nya sebagai milikNya dan diwakili oleh para murid-Nya. ${ }^{40}$

Jadi 'gereja' pada hakikatnya ialah 'umat Allah' atau 'jemaat Allah' yaitu orang-orang yang telah dipanggil keluar dari dunia melalui karya Kristus untuk mengalami persekutuan dengan Dia pada masa kini dan masa yang akan datang. Gereja bersifat 'universal' karena meliputi seluruh orang percaya di muka bumi. Karena itu, gereja juga dituntut agar kehadirannya di dunia ini menjadi representasi Allah dengan turut memproklamasikan keselamatan dari Allah melalui Yesus Kristus.

Dengan demikian tidak dapat dipisahkan antara Kristus dan gereja. Kristus adalah Kepala Gereja dan Gereja adalah umat-Nya. Dia memerintah di dalam dan melalui Gereja-Nya. Gereja sebagai 'umat yang kudus' yang telah dipanggil keluar dari dunia, namun diutus kembali ke dalam dunia. Karenanya, Gereja berada di dalam konteks dunia. Sebagai bagian integral dari konteks dunia, maka Gereja harus berkorelasi dengan konteks sosial dan kultural di tengah masyarakat sekitarnya. Sebagai Kepala Gereja yang memerintah kerajaan-Nya, Kristus juga tidak menginginkan Gereja-Nya keluar dari konteks kehidupan sosial masyarakat. Donald B. Kraybill menegaskan hal ini,

...kitab-kitab Injil tidak memandang kerajaan itu sebagai sesuatu yang terasing dari bagian masyarakat lainnya, baik secara geografis maupun sosial. Yesus tidak menganjurkan kita menghindar atau menarik diri dari kehidupan sosial. Ia juga tidak mengasumsikan bahwa kerajaan dan dunia terpisah dalam wilayah-wilayah yang terbagi tegas. Aksi kerajaan itu berlangsung di tengah-tengah kehidupan sosial. ${ }^{41}$

Dengan demikian, natur alamiah Gereja membuatnya tidak bisa tidak berinteraksi aktif dengan konteksnya. Interaksi tersebut mewujud dalam karya - karya bersama dengan orang lain yang tidak seetnis atau seagama. George V. Pixley menyebutkan lebih konkrit demikian,

\footnotetext{
${ }^{39}$ Louis Berkhof, Systematic Theology (Edinburg: The Banner of Truth Trust, 1976), 555.

${ }^{40}$ Donald Guthrie, Teologi Perjanjian Baru, Jilid 3 (Jakarta: BPK Gunung Mulia, 1992), 27-28, 34.

${ }^{41}$ Donald B. Kraybill, Kerajaan Yang Sungsang (Jakarta: BPK Gunung Mulia, 1993), 3.
} 
Dalam pengertian abstrak dan umum kerajaan Allah dalam Alkitab berarti satu masyarakat yang adil, makmur dan yang memandang semua manusia sederajat. Dalam arti konkret, kerajaan Allah mendorong berbagai proyek historis dalam bermacammacam keadaan. Dalam dua momen permulaan kerajaan berarti pembebasan, satu perjuangan melawan sistem-sistem penjejangan sosial yang memeras kaum pekarya Israel. $^{42}$

Di sinilah Gereja harus kreatif dalam melaksanakan panggilannya untuk percaya dan melayani secara seimbang di tengah dunia. Gereja dituntut tanggung jawab yang besar untuk melibatkan diri sepenuhnya dalam kehidupan sosial yang sama nilainya dengan aspek rohani. ${ }^{43}$ Jadi, Kristus yang telah memanggil Gereja-Nya keluar dari dunia, namun mengutusnya kembali ke dalam dunia, menghendaki agar Gereja-Nya berinteraksi melalui karya nyata di tengah masyarakat. Hakikat naturalitas Gereja inilah yang juga dapat menjadi dasar untuk berinteraksi dengan multietnis dan multireligi.

\section{Multikulturalitas Kekekalan (Aspek Eskatologis)}

Karya penebusan Kristus yang diteruskan oleh dinamika karya Roh Kudus telah melahirkan Gereja Perjanjian Baru yang bersifat 'multikultural'. Hingga perkembangannya saat ini Gereja terus menjadi semakin 'multikultural', seperti disinyalir bahwa,

Dalam tahun-tahun belakangan ini maka persoalan budaya dan pluralismenya sudah menjadi masalah yang sangat besar di seluruh dunia (hal ini juga berhubungan dengan migrasi dan globalisasi). Banyak gereja sekarang memasuki situasi di mana gereja memiliki jemaat yang berasal dari budaya yang beragam dan karenanya gereja terdorong untuk menjadi lebih multi-cultural. ${ }^{44}$

Kondisi Multikulturalitas Gereja ini akan terus berlanjut hingga kekekalan. Pada masa eskatologis, dimana Gereja-Nya telah mengalami pengudusan sempurna, setelah kedatangan Kristus, Sang Kepala Gereja, untuk kedua kalinya, maka Gereja-Nya juga memasuki masa kemuliaan di hadapan tahta Bapa yang kekal. Di sanalah multikulturalitas Gereja menyemarakkan suasana kemuliaan, sebagaimana digambarkan oleh Yohanes dalam kitab Wahyu 7:9-10 demikian:

"Kemudian daripada itu aku melihat: sesungguhnya, suatu kumpulan besar orang banyak yang tidak dapat terhitung banyaknya, dari segala bangsa dan suku dan kaum dan bahasa, berdiri di hadapan tahta dan di hadapan Anak Domba, memakai jubah putih dan memegang daun-daun palem di tangan mereka. Dan dengan suara nyaring mereka berseru: "Keselamatan bagi Allah kami yang duduk di atas tahta dan bagi Anak Domba"

\footnotetext{
${ }^{42}$ George V. Pixley, Kerajaan Allah (Jakarta: Gunung Mulia, 1998), 92.

43 Albert Terril Rasmussen, Christian Social Ethics, Exerting Christian Influence (Englewood: Prenctice, 1956),70-72, 266.

${ }^{44}$ Agus Gunawan Satyaputra, Gereja, Budaya dan Misi dalam Jurnal Teologi: Stulos (Bandung: STTB, 2002),
} 100. 
Multikulturalitas kekekalan di hadapan Anak Domba (Kristus) ini juga menjadi landasan Kristologis bagi orang percaya masa kini bahwa Allah sangat memberi tempat bagi multikulturalitas umat-Nya. Ini menjadi motivasi bagi gereja masa kini untuk terus memberitakan kabar baik kepada segala bangsa dan suku bangsa (multietnis).

\section{PENUTUP:}

Diversitas humanitas mesti dipandang sebagai kreatifitas Allah yang patut dihargai sebagaimana Allah menghargainya sebagai 'gambar dan rupa'-Nya sendiri. Diskriminasi humanitas justru bukti sikap antagonis terhadap otoritas penciptanya. Radikalisme doktrin yang 'melulu' berorientasi pada kebenaran vertikal harus dibarengi dengan pemahaman horisontalnya. Kebenaran sejati justru menjadi utuh ketika kedua aspek tersebut diposisikan secara proporsional. Perbedaan bukan alasan untuk saling melawan dan menghancurkan, karena kasih kepada Tuhan dan sesama bukanlah kebenaran yang dapat dipisahkan sama sekali.

Allah sendiri telah berbuat baik kepada semua orang sesuai hakikat Diri-Nya sendiri sebagai Pencipta segalanya. Allah juga menghendaki agar manusia, yang telah diciptakan dalam gambar dan rupa-Nya, saling melakukan perbuatan baik. Semua manusia memiliki tanggung jawab bersama selama kehidupannya di dunia ini, sehingga dibutuhkan solidaritas dengan sesama. Melalui interaksi yang baik justru dimungkinkan adanya 'point of contact' bagi Injil, sehingga dapat terjadi transformasi kesadaran terhadap hakikat kebenaran Injil yang meresap ke segala aspek hidup manusia seperti 'garam' mengasinkan dunia yang tawar (Mat 5:13). Teologi Multikultural melandasi sikap Kristen untuk berelasi dengan semua orang dalam segala bentuk perbedaannya tanpa kehilangan jati diri (keunikan) kekristenannya. Seorang yang berhati hamba dan berjiwa misioner adalah mereka yang berdiri teguh pada keyakinan imannya kepada Kristus dan bersamaan dengan itu mereka juga orang-orang yang 'memancarkan' terang Kristus melalui 'perbuatan baiknya' bagi sesamanya manusia.

\section{DAFTAR PUSTAKA}

Agus Gunawan Satyaputra, Gereja, Budaya dan Misi dalam Jurnal Teologi: Stulos. Bandung: STTB, 2002.

Albert Terril Rasmussen, Christian Social Ethics, Exerting Christian Influence. Englewood: Prenctice, 1956.

A.M. Hunter, Menafsirkan Perumpamaan-perumpamaan Yesus. Jakarta: BPK Gunung Mulia, 2000.

Archibal A. Hodge, The Atonement. London: Evangelical Pree, 1974. 
Barclay M. Newman, A Concise Greek-English Dictionary Of The New Testament. London: United Bible Societies, 1971.

Charles L. Allen, God's Psichiatry. New Jersey: Fleming H. Revell Company, 1970.

Colin Brown, The New International Dictionary of New Testament Theology, Vol. 2. Grand Rapids, Michigan: Zondervan Publishing House, 1976.

David Wenham, The Parables of Jesus: Pictures of Revolution. London: Hodder \& Stoughton, 1989.

Donald B. Kraybill, Kerajaan Yang Sungsang. Jakarta: BPK Gunung Mulia, 1993.

Donald Guthrie, Teologi Perjanjian Baru, Jilid 1-3. Jakarta: BPK Gunung Mulia, 1992.

Elisa B. Surbakti, Benarkah Yesus Juruselamat Universal? Jakarta: BPK Gunung Mulia, 2006.

Ernst Troeltsch, Protestanism and Progres, A History of the Relation of Protestanism to the Modern World. Beacon: Beacon, 1958.

Gerhart Kittel (Ed.), Theological Dictionary of New Testament, Vol. 1. Grand Rapids, Michigan: Wm.B. Eerdmans Publishing Company, tt.

George Eldon. Ladd, Crucial Question About The Kingdom of God. Grand Rapids, Michigan: Wm.B. Eerdmans Publishing Company, 1952.

George Eldon Ladd, Injil Kerajaan. Malang: Gandum Mas, 1999.

George Eldon Ladd, A Theology of The New Testament. Grand Rapids, Michigan: Wm. B. Eerdmans Publishing Company, 1987.

George V. Pixley, Kerajaan Allah. Jakarta: Gunung Mulia, 1998.

Hasan Susanto (Penyusun), Perjanjian Baru Interlinear Yunani-Indonesia. Jakarta: LAI, 2003.

Herman Ridderbos, The Coming of The Kingdom. Philadelphia: Presbyterian and Reform Publishing Company, 1973.

Herman Ridderbos dan Baarlink, Pemberitaan Yesus Menurut Injil Sinoptis. Jakarta: BPK Gunung Mulia, 1975.

H. Henry Meeter, The Sovereignty of The Social Sphere. Michigan: Baker, 1975.

J. Garang (Peny.), Peranan Agama-agama dan Kepercayaan Terhadap Tuhan yang Maha Esa Dalam Negara Pancasila yang Membangun. Jakarta: BPK Gunung Mulia, 1996.

J.L.Ch. Abineno, Roh Kudus dan Pekerjaan-Nya. Jakarta: BPK Gunung Mulia, 1982.

John Stott, Isu-isu Global Menantang Kepemimpinan Kristiani. Jakarta: Yayasan Komunikasi Bina Kasih, 1984.

Josias L. Lengkong, Jihad Kristen: Adakah kesamaan Jihad Islam dan Jihad Kristen? Jakarta: Yayasan Misi Global Kalimatullah, 2003.

Leon Morris, The New International Commentary on The New Testament: The Gospel According to John. Granda Rapdis, Michigan: Wm.B Eerdmans Publishing Company, 1977.

Louis Berkhof, Teologi Sistematika 3: Doktrin Kristus. Jakarta: LRII, 1998.

Louis Berkhof, Systematic Theology. Edinburg: The Banner of Truth Trust, 1976. 
Matthew Henry, Matthew's Henry Commentary. Grand Rapids, Michigan: Zondervan Publishing Company, 1979.

Peter Wongso, Kristologi. Malang: SAAT, 1988.

Peter Wongso, Hermeneutika Eskatologi. Malang: SAAT, 1989.

Robert L. Thomas (Ed.), New American Standard Exhaustive Concordance of The Bible. Nashville: Holman Bible Publisher, 1981.

Ulrich Beyer, Garis-garis Besar Eskatologi Dalam Perjanjian Baru. Jakarta: BPK Gunung Mulia, 1982.

W.E. Best, Christ's Kingdom Is Future, Vol. II. Houston, Texas: South Belt Assembly of Christ, tt.

Weinata Sairin (Peny.), Kerukunan Umat Beragama Pilar Utama Kerukunan Berbangsa. Jakarta: BPK Gunung Mulia, 2006.

William Hendriksen, New Testament Commentary: The Gospel of John. Edinburg: The Banner Truth Trust, 1959. 


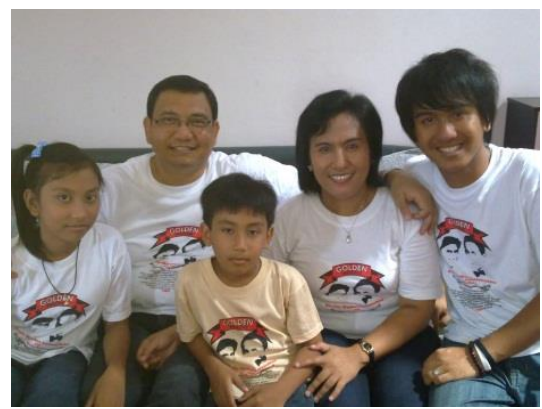

Nama: Pdt. Dr. G. Sudarmanto.

Isteri: Pdt. Dr. Dina E. Latumahina.

Anak-anak: 1. Altira Immanuel Prasetyo (22 tahun)

2. Dorothea Agatha Dwyastri (16 tahun)

3. Bryan Jesaia Zabdi (11 tahun)

\section{Study:}

Sarjana Theologia (S.Th): 1990 di Institut Injil Indonesia, Batu, Jawa Timur. Master of Divinity (M.Div): 1994 di Institut Injil Indonesia, Batu, Jawa Timur. Master of Theology (M.Th): 2001 di Institut Injil Indonesia, Batu, Jawa Timur. Doktor Theologia (D.Th): 2008 di STT Baptis Semarang, Jawa Tengah.

Doctor of Christian Leadership (DCL) di Institut Injil Indonesia, Batu (in Proccess) Doctor of Philosophy (Ph.D) di Asia Graduate School of Theology (AGST) Manila, Philipine (in Proccess)

\section{Pelayanan:}

1991-1994: Pembantu Rektor II Seminari Theologia Tanjung Enim, Sum-Sel (STTE). 1994-2002: Ketua Umum Sinode Gereja Protestan Injili Nusantara (GPIN). 2002-2010: Ketua Sekolah Tinggi Theologia Ebenhaezer, Tanjung Enim, Sum-Sel. 2010-2011: Sekretaris Umum YPPII Batu, Jawa Timur. 2011-2013: Pembantu Rektor II Institut Injil Indonesia, Batu, Jawa Timur. 2013- Sekarang: Rektor Institut Injil Indonesia Batu, Jawa Timur. 
